\title{
Understanding Advanced Organic and Analytical Chemistry
}

The Learner's Approach 
This page intentionally left blank 


\title{
Understanding Advanced Organic and Analytical Chemistry \\ The Learner's Approach
}

\author{
Kim Seng Chan \\ BSc (Hons), PhD, PGDE (Sec), MEd, MA (Ed Mgt), MEd (G Ed) \\ Jeanne Tan
}

BSc (Hons), PGDE (Sec), MEd (LST)

WSeducation

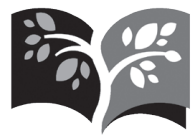


Published by

World Scientific Publishing Co. Pte. Ltd.

5 Toh Tuck Link, Singapore 596224

USA office: 27 Warren Street, Suite 401-402, Hackensack, NJ 07601

UK office: 57 Shelton Street, Covent Garden, London WC2H 9HE

\section{British Library Cataloguing-in-Publication Data}

A catalogue record for this book is available from the British Library.

\section{UNDERSTANDING ADVANCED ORGANIC AND ANALYTICAL CHEMISTRY The Learners' Approach}

Copyright (C) 2012 by World Scientific Publishing Co. Pte. Ltd.

All rights reserved. This book, or parts thereof, may not be reproduced in any form or by any means, electronic or mechanical, including photocopying, recording or any information storage and retrieval system now known or to be invented, without written permission from the Publisher.

For photocopying of material in this volume, please pay a copying fee through the Copyright Clearance Center, Inc., 222 Rosewood Drive, Danvers, MA 01923, USA. In this case permission to photocopy is not required from the publisher.

ISBN-13 978-981-4374-98-9 (pbk)

ISBN-10 981-4374-98-9 (pbk)

Typeset by Stallion Press

Email: enquiries@stallionpress.com

Printed in Singapore. 


\section{Preface}

The majority of the learning of organic chemistry in classrooms happens with the help of textbooks and lecture notes. Unfortunately, most textbooks are of the expository and non-refutational type, presenting facts rather than explaining them. In addition, the links between concepts are often not made explicit, presupposing that learners would be able to make the necessary integration with the physical chemistry concepts they have come across, forgetting that some learners lack the prior knowledge and metacognitive skills to do so. Hence, learners would at most be able to reproduce the information that is structured and organized by the textbook writer, but not able to construct a meaningful conceptual mental model for oneself.

This current book is a continuation of our first book, Understanding Advanced Physical Inorganic Chemistry, retaining the main refutational characteristics of the first book by strategically planting think-aloud questions to promote conceptual understanding, knowledge construction and discourse opportunities. It is hoped that these essential questions will make learners aware of the possible conflict between their prior knowledge, which may be counter intuitive or misleading with those presented in the text, and hence in the process, make the necessary conceptual changes. In essence, we are trying to effect metaconceptual awareness - awareness of the theoretical nature of one's thinking — while learners are trying to master organic chemistry concepts. We hope that by pointing out the differences between possible misconceptions and the actual chemistry content, we can promote metaconceptual awareness and thus assist 
the learner in constructing a meaningful conceptual model of understanding for organic chemistry. We want our learners to not only know what they know, but at the same time have a sense of how they know what they know, and how their new learning is interrelated within the discipline.

Lastly, the substance of this book would be both informative and challenging to the practices of teachers. This book would certainly illuminate the teaching of all chemistry teachers that strongly believe in teaching organic chemistry with a meaningful and integrative approach, from the learners' perspective. The integrated questions at the end of each chapter will certainly prove useful to students in helping them to revise fundamental concepts learnt from previous chapters and also to see the importance and relevance in the application to their current learning. Collectively, this book offers a vision of understanding organic chemistry meaningfully and fundamentally from the learners' approach and to fellow chemistry teachers, we hope that it will help you develop a greater insight into what makes you tick, explain, enthuse and develop in the course of your teaching. 


\section{Acknowledgements}

We would like to express our sincere thanks to the staff at World Scientific Publishing Co. Pte. Ltd. for the care and attention which they have given to this book, particularly our editors Lim Sook Cheng and Sandhya Devi, our editorial assistant Chow Meng Wai and Stallion Press.

We also wish to take this opportunity to express our gratitude to Yeo Yam Khoon of Raffles Institution (Year 5-6) who has been and will always be an inspiration for his unwavering commitment to the teaching of chemistry. Special thanks to Tham Zisheng of Raffles Institution (Year 5-6) for some of his invaluable suggestions.

Special thanks go to all our students who have made our teaching of chemistry fruitful and interesting. We have learnt a lot from them just as they have learnt some good chemistry from us.

Finally, we thank our families for their wholehearted support and understanding throughout the period of writing this book. 
This page intentionally left blank 


\section{Contents}

Preface $\quad$ v

Acknowledgements vii

1. Structure and Bonding 1

1.1 Introduction . . . . . . . . . . . . . . . 1

1.2 Structural Formulae of Organic Compounds . . . 3

1.3 Bonding and Shapes of Organic Molecules . . . . 6

1.3.1 $\mathrm{sp}^{3}$ Hybridization . . . . . . . . . 8

1.3.2 $\mathrm{sp}^{2}$ Hybridization . . . . . . . . . . . 9

1.3.3 sp Hybridization . . . . . . . . . . . . . . . 11

1.3.4 Delocalized Bonding/Resonance . . . . . 13

1.4 Bonding and Reactivity of Organic

Compounds . . . . . . . . . . . . 15

1.4.1 Nature and Strength of Covalent

Bonds . . . . . . . . . . . . . 15

1.4.2 Types of Intermolecular Attractive

Forces . . . . . . . . . . . . . 18

1.4.3 Bonding and Physical Properties of Organic Compounds . . . . . . . . . 22

2. Isomerism in Organic Compounds 29

2.1 Introduction . . . . . . . . . . . . . . . . . . . . 29

2.2 Structural Isomerism . . . . . . . . . . . . 30

2.2 .1 Chain Isomerism . . . . . . . . . . . 30 
2.2.2 Positional Isomerism . . . . . . . . . . 31

2.2.3 Functional Group Isomerism . . . . . . . 34

2.3 Stereoisomers . . . . . . . . . . . . . 35

2.3.1 Geometrical Isomerism (cis-trans Isomerism) . . . . . . . . . . . . . 37

2.3.2 Conformational Isomerism . . . . . . . 43

2.3.3 Optical Isomerism . . . . . . . . . . . 46

3. Organic Reactions and Mechanisms 61

3.1 Introduction . . . . . . . . . . . . . . . . 61

3.2 Types of Bond Cleavage . . . . . . . . . . 67

3.2.1 Homolytic Bond Cleavage . . . . . . . . . 68

3.2.2 Heterolytic Bond Cleavage . . . . . . . 69

3.2.3 Type of Reaction Intermediates . . . . . 70

3.3 Types of Organic Reactions . . . . . . . . . . 73

3.3.1 Rearrangement Reactions . . . . . . . . . 74

3.3.2 Redox Reactions . . . . . . . . . . . . 74

3.3.3 Addition Reactions . . . . . . . . . . . . . 74

3.3.4 Elimination Reactions . . . . . . . . . . 75

3.3.5 Substitution Reactions . . . . . . . . 76

3.4 Types of Reaction Mechanisms . . . . . . . 76

3.4.1 Electrophilic Addition Mechanism . . . . 77

3.4.2 Nucleophilic Addition Mechanism . . . . 81

3.4.3 Free Radical Substitution Mechanism . . 86

3.4.4 Electrophilic Substitution Mechanism . . 88

3.4.5 Nucleophilic Substitution Mechanism . . 92

4. Alkanes 105

4.1 Introduction . . . . . . . . . . . . 105

4.2 Nomenclature . . . . . . . . . . . . . 106

$4.3 \quad$ Physical Properties . . . . . . . . . . . . . . 110

4.3.1 Melting and Boiling Points . . . . . . . . 110

4.3.2 Solubility . . . . . . . . . . . . 112

4.4 Preparation Methods . . . . . . . . . . . . 112

4.4.1 Catalytic Hydrogenation of Alkenes . . . 112

4.5 Chemical Properties . . . . . . . . . . . . . 113

4.5.1 Combustion - Oxidation . . . . . . . 113 


\subsubsection{Halogenation — Free Radical} Substitution ............ 115

4.5.3 Thermal and Catalytic Cracking . . . . . 119

5. Alkenes

5.1 Introduction . . . . . . . . . . . . . 123

5.2 Nomenclature . . . . . . . . . . . . . 123

5.3 Physical Properties . . . . . . . . . . . . . 127

5.3.1 Melting and Boiling Points . . . . . . . 127

$5.3 .2 \quad$ Solubility . . . . . . . . . . . . 130

5.4 Preparation Methods . . . . . . . . . . . . 130

5.4.1 Dehydration of Alcohols . . . . . . . . 130

5.4.2 Dehydrohalogenation of

Halogenoalkanes . . . . . . . . . . . . 132

$5.5 \quad$ Chemical Properties . . . . . . . . . . . 133

5.5.1 Catalytic Hydrogenation -

Reduction ............ 133

5.5.2 Formation of Halogenoalkane -

Electrophilic Addition . . . . . . . . . 135

5.5.3 Formation of Dihalide — Electrophilic

Addition . . . . . . . . . . . 139

5.5.4 Formation of Halohydrin — Electrophilic Addition . . . . . . . . . . . 139

5.5.5 Formation of Alcohol - Electrophilic Addition . . . . . . . . . . . . 142

5.5.6 Combustion - Oxidation . . . . . . . . 144

5.5.7 Formation of Diol - Oxidation . . . . . 144

5.5.8 Formation of Carbon Dioxide, Ketone and Carboxylic Acid - Oxidation . . . . 145

5.5.9 Formation of Aldehyde and Ketone -

Oxidation . . . . . . . . . . . . 148

$5.6 \quad$ Summary . . . . . . . . . . . . . . . 149

6. Arenes 153

$6.1 \quad$ Introduction . . . . . . . . . . . . . . 153

6.2 Nomenclature . . . . . . . . . . . . . . . . . . 158

6.3 Physical Properties . . . . . . . . . . . . 159 
6.3.1 Melting and Boiling Points . . . . . . . 159

6.3.2 Solubility . . . . . . . . . . . . . 159

6.4 Chemical Properties of Benzene . . . . . . . . . 160

6.4.1 Formation of Halogenoarene -

Electrophilic Substitution . . . . . . . . 160

6.4.2 Formation of Alkylbenzene -

Electrophilic Substitution . . . . . . . . 161

6.4.3 Formation of Nitrobenzene -

Electrophilic Substitution . . . . . . . . 163

6.4.4 Catalytic Hydrogenation -

Reduction ............ 165

6.4.5 Combustion - Oxidation . . . . . . . 166

6.5 Benzene Derivatives . . . . . . . . . 166

6.5.1 The Influence of the Substituent

on the Rate of Electrophilic

Substitution . . . . . . . . . 166

6.5.2 The Influence of the Substituent on the

Orientation of Electrophilic Attack . . . . 171

6.6 Chemical Properties of Methylbenzene . . . . . . 175

6.6.1 Formation of Halogenoarene -

Electrophilic Substitution . . . . . . . . 175

6.6.2 Formation of Alkyl(Methylbenzene) -

Electrophilic Substitution . . . . . . . 176

6.6.3 Formation of Nitroarene - Electrophilic

Substitution . . . . . . . . . 176

6.6.4 Halogenation — Free Radical

Substitution (at Alkyl Side-Chain) . . . . 179

6.6.5 Formation of Benzoic Acid - Oxidation

(at Alkyl Side-Chain) . . . . . . . . . . . . 180

6.7 Summary . . . . . . . . . . . . 182

7. Halogen Derivatives 185

$7.1 \quad$ Introduction . . . . . . . . . . . . . 185

7.2 Nomenclature . . . . . . . . . . . . . . . . 185

$7.3 \quad$ Physical Properties . . . . . . . . . . . . . 187

7.3.1 Melting and Boiling Points . . . . . . . 187

$7.3 .2 \quad$ Solubility . . . . . . . . . . 188 
7.4 Preparation Methods for Halogenoalkanes . . . . 188

7.4.1 Nucleophilic Substitution of Alcohols . . 188

7.4.2 Formation of Halogenoalkane -

Electrophilic Addition . . . . . . . . . . . 189

7.4.3 Formation of Dihalide -

Electrophilic Addition . . . . . . . . . . . 191

7.5 Chemical Properties of Halogenoalkanes . . . . . 192

7.5.1 Formation of Alcohol — Nucleophilic

Substitution . . . . . . . . . . 193

7.5.2 Formation of Nitrile - Nucleophilic

Substitution . . . . . . . . . 195

7.5.3 Formation of Amine - Nucleophilic

Substitution . . . . . . . . . 197

7.5.4 Formation of Ether - Nucleophilic

Substitution ............ 200

7.5.5 Formation of Alkene Via

Dehydrohalogenation — Elimination . . . 201

7.6 Halogenoalkanes versus Halogenoarenes . . . . . 204

7.7 Preparation Methods for Halogenoarenes . . . . . 206

7.7.1 Formation of Halogenoarene -

Electrophilic Substitution . . . . . . . 206

7.8 Chemical Properties of Halogenoarenes . . . . . . 206

7.8.1 Formation of Benzene Derivatives -

Electrophilic Substitution . . . . . . . 206

7.9 Summary . . . . . . . . . . . . 207

8. Alcohols and Phenol 211

8.1 Introduction . . . . . . . . . . . . . . 211

8.2 Nomenclature . . . . . . . . . . . . . . 212

8.3 Physical Properties . . . . . . . . . . . . 213

8.3.1 Melting and Boiling Points . . . . . . . 213

8.3.2 Solubility . . . . . . . . . . . . . . 214

8.4 Hydrolysis and Acidity . . . . . . . . . . . 217

8.5 Preparation Methods for Alcohols . . . . . . . 233

8.5.1 Electrophilic Addition of Alkenes . . . . 233

8.5.2 Nucleophilic Substitution of

Halogenoalkanes . . . . . . . . . . . . 234 


\subsubsection{Reduction of Carboxylic Acids} and Carbonyl Compounds . . . . . . . 234

8.6 Chemical Properties of Alcohols . . . . . . . . 235

8.6.1 Acid-Base Reaction with Strong Bases and Reactive Metals . . . . . . . . . 235

8.6.2 Formation of Esters with Carboxylic

Acids - Esterification via Nucleophilic Substitution ........... . 237

8.6.3 Formation of Esters with Acid

Chlorides - Acylation via Nucleophilic Substitution ............ . 239

8.6.4 Formation of Alkenes — Dehydration . . 240

8.6.5 Formation of Halogenoalkanes -

Nucleophilic Substitution . . . . . . . . 243

8.6.6 Formation of Carbonyl Compounds and Carboxylic Acids - Oxidation . . . 245

8.6.7 Formation of Tri-Iodomethane (Iodoform) - Oxidation . . . . . . . . 249

8.7 Chemical Properties of Phenol . . . . . . . . 250

8.7.1 Acid-Base Reaction with Strong Bases and Reactive Metals . . . . . . . . . . 251

8.7.2 Formation of Esters with Acid Chlorides - Acylation . . . . . . . . 251

8.7.3 Formation of Halogenophenol Electrophilic Substitution . . . . . . . . 252

8.7.4 Formation of Nitrophenol - Electrophilic Substitution . . . . . . . . . 254

8.7.5 Test for Phenol . . . . . . . . . . 255

8.8 Summary . . . . . . . . . . . . . . . . 256

9. Carbonyl Compounds 261

9.1 Introduction . . . . . . . . . . . . . 261

9.2 Nomenclature . . . . . . . . . . . . . . 262

9.3 Physical Properties . . . . . . . . . . . . . . . 262

9.3.1 Melting and Boiling Points . . . . . . . 262

9.3.2 Solubility . . . . . . . . . . . . 263 
9.4 Preparation Methods for Carbonyl

Compounds . . . . . . . . . . . . . . 264

9.4.1 Oxidation of Alcohols . . . . . . . . . 264

9.4 .2 Oxidation of Alkenes . . . . . . . . . . 264

9.4.3 Ozonolysis - Oxidation of Alkenes . . . 265

9.5 Chemical Properties of Carbonyl

Compounds . . . . . . . . . . . . 265

9.5.1 Formation of Cyanohydrins -

Nucleophilic Addition . . . . . . . . . . 266

9.5.2 Condensation Reaction (Addition-

Elimination Reaction) . . . . . . . . 267

9.5.3 Formation of Carboxylic Acid -

Oxidation . . . . . . . . . . . 270

9.5.4 Formation of Carboxylate Salts Using

Tollen's Reagent - Oxidation . . . . . . 271

9.5.5 Formation of Carboxylate Salts using

Fehling's Reagent - Oxidation of

Aliphatic Aldehydes . . . . . . . . . . 273

9.5.6 Formation of Tri-Iodomethane

(Iodoform) - Oxidation . . . . . . . . 275

9.5.7 Formation of Alcohols — Reduction . . . 277

9.6 Aromatic Carbonyl Compounds . . . . . . . . . . 279

9.7 Summary . . . . . . . . . . . . . . . . . 280

10. Carboxylic Acids and Their Derivatives 287

10.1 Introduction . . . . . . . . . . . . . . . . 287

10.2 Nomenclature . . . . . . . . . . . . . 287

10.3 Physical Properties . . . . . . . . . . . . . . . . 288

10.3.1 Melting and Boiling Points . . . . . . . 288

10.3.2 Solubility . . . . . . . . . . . . . . . 291

10.4 Preparation Methods for Carboxylic

Acids . . . . . . . . . . . . . . . . . 291

10.4.1 Oxidation of Primary Alcohols . . . . . . 291

10.4.2 Oxidation of Aldehydes . . . . . . . . . 291

10.4.3 Oxidation of Alkenes . . . . . . . . . . 292

10.4.4 Hydrolysis of Nitriles . . . . . . . . . . . 292

10.4.5 Oxidation of Alkylbenzene . . . . . . . . 293 
10.5 Chemical Properties of Carboxylic Acids . . . . . 293 10.5.1 Acid-Base Reaction with Strong Bases and Reactive Metals . . . . . . . . . 295

10.5.2 Formation of Acyl Chlorides Nucleophilic Substitution . . . . . . . . 296

10.5.3 Formation of Esters with Alcohols Esterification via Nucleophilic Substitution . . . . . . . . . . 297

10.5.4 Reduction of Carboxylic Acids to Primary Alcohols . . . . . . . . . . . 297

10.6 Derivatives of Carboxylic Acids . . . . . . . . . . 298 10.6.1 Nomenclature . . . . . . . . . . . . . 299 10.6.2 Physical Properties . . . . . . . . . . . 299 10.6.3 Chemical Properties . . . . . . . . . . . 300 10.6.4 Chemistry of Acid Chlorides . . . . . . . 302 10.6.5 Chemistry of Esters . . . . . . . . . . 307 10.6.6 Chemistry of Amides . . . . . . . . . . 310

10.7 Summary . . . . . . . . . . . . . . 312

11. Amines 321

11.1 Introduction . . . . . . . . . . . . . . . . . 321

11.2 Nomenclature . . . . . . . . . . . . . . . . 321

11.3 Physical Properties . . . . . . . . . . . . . . . . 322

11.3.1 Melting and Boiling Points . . . . . . . . 322

11.3.2 Solubility . . . . . . . . . . . . . . . 324

11.3.3 Basicity . . . . . . . . . . . . . . . . . . . . . . . . . . . . . . . . . .

11.4 Preparation Methods for Amines . . . . . . . . 328

11.4.1 Nucleophilic Substitution of Halogenoalkanes . . . . . . . . . . . 328

11.4.2 Reduction of Amides . . . . . . . . . . . 329

11.4.3 Reduction of Nitriles . . . . . . . . . . . 329

11.4.4 Reduction of Nitrobenzene . . . . . . . . 330

11.5 Chemical Properties . . . . . . . . . . . . 331

11.5.1 Acid-Base Reaction with Acids . . . . . 331

11.5.2 Formation of Amides with Acid Chloride - Acylation via Nucleophilic Substitution . . . . . . . . . 332 
11.5.3 Formation of Amides with Esters -

Nucleophilic Substitution . . . . . . . . 332

11.5.4 Formation of Amine - Nucleophilic

Substitution ............ . 333

11.5.5 Formation of Halogenophenylamine -

Electrophilic Substitution . . . . . . . . 334

11.5.6 Reaction of Primary Amine with Nitrous

Acid . . . . . . . . . . 336

11.6 Summary . . . . . . . . . . . 336

12. Amino Acids 341

12.1 Introduction . . . . . . . . . . . . . . . 341

12.2 The Formation of Zwitterions -

An Intramolecular Acid-Base Reaction . . . . . . 347

12.3 Physical Properties of Zwitterions . . . . . . . . . 349

12.3.1 Melting and Boiling Points . . . . . . . . 349

12.3.2 Solubility . . . . . . . . . . . . 349

12.4 Chemical Properties of Zwitterions . . . . . . . . 350

12.4.1 Acid-Base Reaction with Acids

or Bases . . . . . . . . . . . 350

12.4.2 Formation of Amides . . . . . . . . . . 359

12.4.3 Polymerization - Reaction between

Amino Acids . . . . . . . . . . . . . . . 360

13. Polymers 363

13.1 Introduction . . . . . . . . . . . . . . 363

13.2 Addition Polymers . . . . . . . . . . . . 368

13.2.1 Free Radical Polymerization of Alkene . . 368

13.2.2 Types of Addition Polymers and Their

Properties . . . . . . . . . . 371

13.2.3 Pollution Problems Associated with

Poly(Alkenes) . . . . . . . . . . . . 379

13.3 Condensation Polymers . . . . . . . . . . . 379

13.3.1 Polyesters . . . . . . . . . . . . . . . . . . . . . . . . . . . 380

13.3.2 Polyamides . . . . . . . . . . . . . . 381

13.4 Biological Polymers - Polypeptides

and Proteins . . . . . . . . . . . . . . . . 384 
13.4.1 The Different Levels of Protein Structure . . . . . . . . . . 387

13.4.2 Denaturation of Proteins . . . . . . . 395

14. Mass Spectrometry 405

14.1 Introduction . . . . . . . . . . . . . . . . . 405

14.2 Basic Features of a Mass Spectrometer . . . . . . 407

14.3 Mass Spectrum Analysis . . . . . . . . . . . . . 410

14.4 Analyzing the Mass Spectrum of an Element . . . . . . . . . . . . . . . . 414

14.5 Analyzing the Mass Spectrum of Alkanes . . . . 417

14.6 Analyzing the Mass Spectrum of Chloroalkanes . . . . . . . . . . . . . 422

14.7 Analyzing the Mass Spectra of Isomers . . . . . . 425

14.8 Deducing the Structure of an Unknown

Compound from Mass Spectrum Analysis . . . . 430

15. Ultra-Violet and Visible Spectroscopy 433

15.1 Introduction . . . . . . . . . . . . . . . . 433

15.2 Molecular Orbital Theory (MO Theory) . . . . . 436

15.3 Basic Principles of Spectroscopy . . . . . . . . . . 445

15.4 Types of Spectroscopic Methods . . . . . . . . 450

15.4.1 Ultraviolet-Visible (UV-Vis)

Spectroscopy . . . . . . . . . . . 451

16. Infrared Spectroscopy 457

16.1 Introduction . . . . . . . . . . . . . 457

16.2 What is the Concept of Degree of Freedom? . . . 462

16.3 How is an IR Spectrum for a Molecule

Determined? . . . . . . . . . . . . 465

16.4 Analyzing the IR Spectrum of Simple Molecules . . . . . . . . . . . . . . 466

16.5 Analyzing the IR Spectrum of Organic Molecules . . . . . . . . . . . . . . . 468

17. Nuclear Magnetic Resonance Spectroscopy 477

17.1 Introduction . . . . . . . . . . . . . . . . 477 
17.2 Principal of ${ }^{1} \mathrm{H}$ NMR Spectroscopy . . . . . . . . 483

17.3 How Is a ${ }^{1} \mathrm{H}$ NMR Spectrum

for a Molecule Determined? . . . . . . . . . . . . 485

17.3.1 Chemical Shifts . . . . . . . . . . . 488

17.3.2 Factors that Account for the Relative

Chemical Shifts . . . . . . . . . . 491

17.4 Important Features on the ${ }^{1} \mathrm{H}$ NMR

Spectrum of Organic Molecules . . . . . . . . . . 496

17.4.1 The Number of Signals . . . . . . . . . . 497

17.4.2 The $\delta$ Value of Each Signal . . . . . . . . 497

17.4.3 The Relative Areas under the Peaks . . . 498

17.4.4 The Splitting Patterns of the Signals . . 500

17.5 Analyzing the ${ }^{1} \mathrm{H}$ NMR Spectrum of

Simple Organic Molecules . . . . . . . . . . . . 507

17.6 Labile Protons and Proton Exchange

Reactions . . . . . . . . . . . . . 510

18. Chromatography and Electrophoresis 513

18.1 Introduction . . . . . . . . . . . . . . . . 513

18.2 Paper Chromatography — An Introduction

to Chromatography Technique . . . . . . . . . . 514

18.3 Thin Layer Chromatography (TLC) . . . . . . . 520

18.4 Column Chromatography (CC) . . . . . . . . . 522

18.5 High-Performance Liquid Chromatography (HPLC) . . . . . . . . . . . . . . . 523

18.6 Gas-Liquid Chromatography (GLC) . . . . . . 524

18.7 Electrophoresis . . . . . . . . . . . . 525

Index 